\title{
An innate period of familial preferences in chicks not imprinted ${ }^{1}$
}

PHILIP H. GRAY, STELLA J. SALLEE, and ALLEN T. YATES, ${ }^{2}$ University of Manitoba, Winnipeg, Canada

White Leghorn chicks hatched and reared in visual isolation were tested for innate preferences in a choice situation of age-mate paired against a hen. Thirty-two Ss were tested at each of the following ages: $1,12,24,36,48,60,72$, and $84 \mathrm{~h}$ since hatching. The mean response of the younger Ss was to the hen, but the preference for age-mate increased steadily until a maximum was reached at $36 \mathrm{~h}$ of age post-hatch, when it began to decline, approaching zero preference at $84 \mathrm{~h}$.

It has been noted that young naive birds will imprint more strongly to some targets than to others. For example, a genetics of behavior experiment showed that chicks may follow some objects better on first sight only to imprint better on other objects, with these tendencies being inherited (Gray, Yates, Davis, \& Mode, 1966). Further, an inanimate and unresponsive duck decoy evidently can produce stronger imprinting in ducklings than can a human being, suggesting a specific innate knowledge of the visual characteristics of the species (Hess \& Hess, 1969).

We have known for some years that chicks exhibit innate preferences for colored objects presented in a Latin-square design (Gray, 1961). In that study, each Latin square was analyzed for responses elicited before the presentation of a particular stimulus object as compared with the responses after that object had been experienced. It was speculated there that the response patterns that matured over the 5 days of testing would be biologically appropriate if the chick had instinctive preferences for (or specific innate knowledge of) different members of the natural family. The present experiment was intended to further this initial discovery. Obviously, if there should exist maturational periods of instinctive behavior associated with the critical period of social fixation, then their influence would need to be "factored out" of a study dealing expressly with the effects of early experience.

\section{APPARATUS}

\section{AND STIMULUS OBJECTS}

A battery of four preference testing units was employed. Each unit was $12 \times 16 \times 40 \mathrm{in}$. long, divided into three compartments separated from each other by glass partitions. The center compartment contained a platform pivoted so that a movement of the $S$ approximately 2 in. away from the center, toward either of the end compartments, depressed the platform enough to activate a microswitch starting a dynamically braked lapsed-time meter clocking minutes and 10ths of minutes spent by $S$ on one or the other end of the tilt-platform. The platform had a nonslip surface (fine sand sprinkled on wet paint), and its slight vertical excursions during tilt had no noticeable effect on the young chicks. While the apparatus automatically recorded only gross movements, the side tilted invariably was the end compartment faced by the chick in a two-choice situation such as this. The units were placed side by side, with compartments containing the stimulus objects north and south.

A large stimulus object was one of four adult hens of the White Leghorn breed. They occupied the south compartments. All were in good plumage, and each was maintained in a standing frontal position by a harness hidden under the feathers with transparent nylon guys attached. A small stimulus object was an age-mate placed in the center of its compartment with no restriction on movement.

\section{SUBJECTS}

Eggs from White Leghorn random breeding stock were held at about $40 \operatorname{deg} F$ for at least 2 days. They were then set in a Jamesway forced-air commercial incubator. On the 18th day of setting, the eggs were transferred to a darkroom with $100 \operatorname{deg} \mathbf{F}$ temperature and about $50 \%$ relative humidity. After the first hatchings, the eggs were inspected at $1 / 2-h$ intervals, and any egg about to hatch was placed in a $4 \times 6$ in. visual isolation compartment without food or water. Lights in one isolation room came on at 6:00 a.m. and went off at 6:00 p.m. In a second isolation room, the light cycle was reversed. Ss were alternately assigned to the isolation rooms. PROCEDURE

The Ss were transferred to the testing room in darkness in a sectioned box color-coded to match the exterior colors of the testing units. A pencil-beam flashlight was used to place Ss in the center of the tilt-platform. Pilot lights in the adjacent control room indicated if any $S$ had moved from the center of a platform before the room lights and recording apparatus were turned on. A white-noise generator masked sounds in the testing room; the temperature there was near $80 \mathrm{deg} F$ at all times.

A trial was $15 \mathrm{~min}$ long. The scoring procedure was to treat time spent before the small stimulus object (age-mate) as minuend and time spent before the large stimulus object (hen) as subtrahend, with the difference being the score used in the statistical analysis of discrimination scores. An absolute score was obtained by simply adding minuend and subtrahend without signs; these scores were also subjected to statistical analysis.

\section{EXPERIMENTAL DESIGN}

The apportionment of the 256 Ss was as follows. Half of the $\mathrm{Ss}$ were raised with normal light cycle, half with reversed cycle. There were eight age groups: 1, 12, 24, 36, $48,60,72$, and $84 \mathrm{~h}$ post-hatch. Testing always commenced at four definite periods: 6:00 p.m., midnight, 6:00 a.m., and noon. This factorial design of two light cycles by eight ages by four testing periods had four Ss in each cell. An S was tested once only. Statistical assessment was with analysis of variance, with partitioning of squares as recommended by Edwards (1960).

\section{RESULTS AND DISCUSSION}

The Ss raised with reversed light cycle performed essentially the same as those raised with a normal cycle. Total mean discrimination score for reversed light was $2.94 \mathrm{~min}$ in favor of the age-mate, and that for normal light, $2.50 \mathrm{~min}$ in favor of the age-mate. This slight difference was not significant in the analysis of variance.

In previous experiments, where an $S$ was tested six or eight times through a $24-h$ period, the time-of-day-at-test factor had been significant (Gray, 1962, 1964). Such was not true in the present experiment, where an $S$ was tested once and discarded. The total discrimination mean scores for the four periods of testing were different but not enough to be significant in the analysis of variance. The lowest was 1.48 at $6: 00$ p.m. The midnight mean was 2.72 . The 6:00 a.m. mean was 2.97 . The highest was 3.72 at noon. All means were in favor of the age-mate.

The age factor was extremely significant, beyond the .01 level with an $\mathrm{F}$ of 5.08 , with 7 and $192 \mathrm{df}$. This finding is illustrated in Fig. 1 with the nonsignificant conditions collapsed. Clearly, the hatchling's preference is for the hen, but the chick is not very old before its preference shifts to the age-mate, and this preference increases until $36 \mathrm{~h}$ post-hatch, after which there is a gradual decline.

The parsimonious explanation is that we have here an innate periodicity of behavior. There are several alternative explanations, however, that do not require reference to 


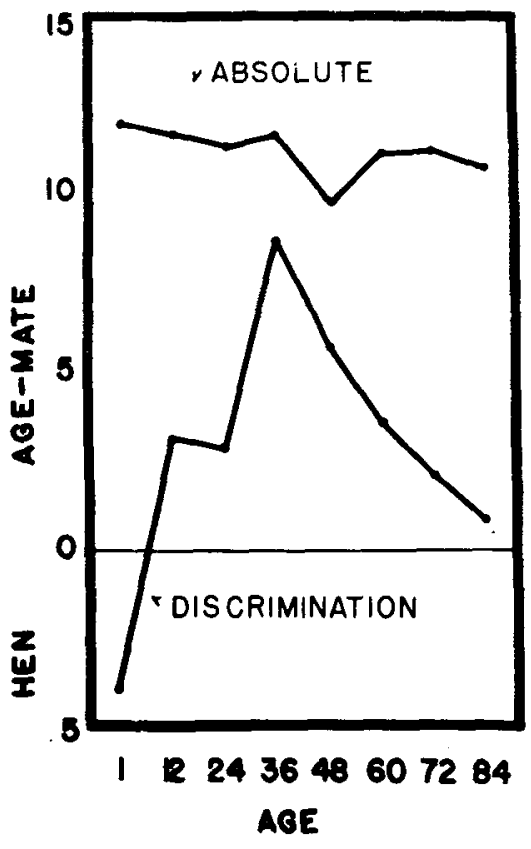

Fig. 1. The lower curve represents the mean average discrimination scores as a function of the age of $S$ at test. The upper curve represents the same scores when these are combined (made absolute) for both hen and age-mate. The independent scores of $32 \mathrm{Ss}$ are included in each point; $\mathrm{N}=256$.

heredity and evolution for a theoretical framework. Let us consider them.

One, since none of the chicks in this experiment was given food or water until after the test, couldn't the demonstrated behavior be due, first, to activity initiated by tissue-need, and second, to malnutrition and loss of motor energy? Answer: The chick's internal source of food, as psychologists have known since Spalding's time, is adequate for 4 or even 5 days after hatching (Gray, 1967). The behavioral signs of malnutrition are listlessness and drooping wings. None of the chicks showed such symptoms and one and all ate normally after their testing; none appeared ill and none died.

Two, could it not be that what we have in Fig. 1 is a progressive preference for the age-mate as a result of CNS arousal, but that, after $36 \mathrm{~h}$ of age, there is less and less responsiveness because of the damping of the arousal system? Answer: To ascertain if such an objection had merit, we added time spent before the age-mate to time spent before the hen. This arrangement of absolute scores is plotted (arbitrarily) on the age-mate side of Fig. 1. We see that the total scores are about the same for the various age groups. Analysis of variance yielded no significant differences.
Therefore, the preference curve at the bottom of the figure is truly a discrimination curve, not an energy curve or an "arousal-damping" curve. This will be easier to understand when we say that the older chicks' lack of preference is indicated not by failure to respond but by indiscriminate responding. Descriptively, a chick older than about $36 \mathrm{~h}$ runs first to the hen and then to the age-mate, back and forth, accumulating about equal scores for each but losing a certain amount of total time because it often crosses the neutral area of the tilt-platform.

Taken at face value, the experiment reported here shows a biphasic familial preference that undoubtedly predicts some of the events that would occur when the hen incubates and mothers her young. The hens used as stimulus objects in this experiment were, of course, not mothers, and it's quite possible that they conveyed to the Ss some of the hostility that nonbroody hens typically exhibit toward young chicks.

It is suggested that the innate factors of imprinting should be isolated and accounted for before differential responsiveness can be ascribed to learning.

\section{RETLRENCES}

EDWARDS, A. L. Experimental design in psychological research. (2nd ed.) New York: Holt, Rinehart \& Winston, 1960.

GRAY, P. H. The releasers of imprinting: Differential reactions to color as a function of maturation. Journal of Comparative \& Physiological Psychology, 1961, 54, 597-601.

GRAY, P. H. Is the imprinting critical period an artifact of a biological clock? Perceptual \& Motor Skills, 1962, 14, 70.

GRAY, P. H. Interactions of temporal and releasing factors in familial recognition of own and ancestral species. Perceptual \& Motor Skills, 1964, 18, 445-448.

GRAY, P. H. Spalding and his influence on research in developmental behavior. Journal of the History of the Behavioral Sciences, 1967 , 3, 168-179.

GRAY, P. H., YATES, A. T., DAVIS, G. T., \& MODE, C. J. Some aspects of the genetics of imprinting. American Zoologist, 1966, 6, 568.

HESS, E. H., \& HESS, D. B. Innate factors in imprinting. Psychonomic Science, 1969, 14, 129-130.

\section{NOTES}

1. The experiment reported here was supported by U.S. Public Health Service Grants MH-05766 and HD-00877 and was conducted in the senior author's Imprinting Laboratory at Montana State University.

2. Stella J. Sallee is now at Willamette University and Allen T. Yates is at Bowling Green State University.

\section{Memory loss following post trial electrical stimulation of the hippocampus ${ }^{1}$}

ROBERT L. BRUNNER, RONALD R. ROSSI, ROBERT M. STUTZ, and THOMAS G. ROTH, University of Cincinnati, Cincinnati, Ohio 45221

Retention of a one-trial passive-avoidance response in rats was found to be disrupted by subconvulsive electrical stimulation of the hippocampus, which was administered immediately following footshock. Lesions of the hippocampus or stimulation of anatomically related areas did not impair performance of the avoidance response significantly.

Although electroconvulsive shock (ECS) may have anterograde effects on retention (Hudspeth \& Gerbrandt, 1965), amnesic changes are probably responsible for interference with performance in one-trial passive-avoidance situations. While it is often assumed that ECS disrupts a neural consolidation process underlying the formation of memory traces (McGaugh, 1966), the locus of action of ECS has recejved only limited experimental attention (Kesner \& Doty, 1967; Hostetter, 1968). A considerable amount of research has accumulated indicating that the brain hippocampi are involved in the integration of information to be stored elsewhere (Penfield \& Milner, 1958; Flexner, Flexner, \& Roberts, 1967; Deutsch, Hamburg, \& Dahl, 1966; Uretsky \& McCleary, 1969). Among recent hypotheses are several that propose that findings of retrograde amnesia produced by ECS depend on disruption of electrical activity in the hippocampus (Hudspeth \& Gerbrandt, 1965; Douglas, 1967; Kimble, 1968; Routtenberg, 1968). Several recent studies (Stein \& Chorover, 1968; Brunner \& Rossi, 1969; Erickson \& Patel, 1969) may be interpreted as showing that localized low-level electrical stimulation delivered to the hippocampus disrupts its functioning. Unlike the earlier experiments, low-level electrical stimulation of short duration was administered following a learning procedure typical of those used in ECS studies of memory.

\section{SUBJECTS, SURGERY, AND HISTOLOGY}

Forty-five male hooded rats (Long-Evans) served as $S s$ in the experiment. Thirty-two of these were implanted with a bipolar stimulating electrode (Stutz, 1968). Eleven Ss received 